\title{
Movimentos, tecnologia e pessoas negras: é possível um outro turismo?
}

\author{
Travel movements, technology and black people: is it \\ another tourism possible?
}

\section{Michel Alves Ferreira}

Doutorando em Tecnologia e Sociedade pela Universidade Tecnológica Federal do Paraná UTFPR, Curitiba/PR, Brasil

E-mail: maferreiragi@gmail.com

\section{Lindamir Salete Casagrande}

Pós-Doutora em Estudos Interdisciplinares Sobre Mulheres, Gênero e Feminismos pela Universidade Federal da Bahia - UFBA, Salvador/BA, Brasil

E-mail: lindasc@utfpr.edu.br 


\section{RESUMO}

Este estudo, de natureza teórico/metodológica qualitativa e bibliográfica, objetiva tecer uma discussão crítica acerca das vivências/experiências de pessoas negras no turismo, tendo como elementos teóricos balizadores centrais os construtos de tecnologia de Andrew Feenberg e o conceito de racismo cotidiano, teorizado por Philomena Essed. Para corroborar com o objetivo central deste artigo e seus argumentos teóricos, buscou-se uma empresa brasileira online de acomodações/hospedagens compartilhadas, voltada especialmente às pessoas negras viajantes. Destarte, foram transcritos três fragmentos de relatos de pessoas negras à empresa analisada, uma vez que estas pessoas vivenciaram situações de discriminação misóginas e/ou racistas ao experienciarem o turismo, seja como visitantes ou anfitriões de hospedagens. Por fim, se buscam possibilidades democráticas e não maniqueístas para responder à pergunta título deste artigo: é possível um outro turismo?

Palavras-chave: Tecnologia. Intersubjetividade. Racismo Cotidiano. Pessoas Negras.

Turismo.

\section{ABSTRACT}

This theoretical and methodological study aims to provide a critical discussion about the experiences of black people in tourism, having as central theoretical elements the constructs of Technology, by Andrew Feenberg and the concept of Everyday Racism, theorized by Philomena Essed. In order to corroborate the central objective of this article and its theoretical arguments, we selected a Brazilian online accommodation / shared lodging company, especially aimed for the black people travelers. In this way, three reports of black people were transcribed, supplied to the company analyzed, since these people experienced misogynist and / or racist discriminations as tourists, either as visitors or as hosts of accommodations. Finally, we look for democratic and non-Manichaean possibilities to answer the title question of this article: is it possible to have another tourism?

Keywords: Technology. Intersubjectivity. Daily Racism. Black People. Tourism. 


\section{INTRODUÇÃO}

Pensar o turismo enquanto um fenômeno sócio/cultural requer refletir sobre construções e constituições constantes de significados realizados pelos/para os próprios sujeitos, em uma perspectiva interpretativa fragmentada e multi/interdisciplinar. Significa dizer, nesta interpretação posta, que o fenômeno turístico objetiva valorar as experiências individuais e coletivas de cada pessoa, mediante os interesses e influências de cada grupo social envolvido nesta dinâmica: estado, mercado, comunidades e visitantes, onde nem sempre estas relações ocorrem sem maiores conflitos, disputas e/ou rupturas (Ferreira \& Casagrande, 2018; Krippendorf, 2001; Moesch, 2002). A interpretação cultural dialética/dialógica ${ }^{1}$ aqui é a chave para se pensar em um turismo como fenômeno.

Deste modo, é possível afirmar que a experiência turística é notória e pública para cada viajante justamente porque o seu significado é interpretativo e intersubjetivo ${ }^{2}$. A intenção é fugir da cotidianidade, mas, ao mesmo tempo, o viajante recria no destino turístico as suas vivências particulares, combinadas com a interpretação do fenômeno que lhe é oferecida durante sua permanência no lugar.

Neste sentido, cabe salientar também que os artefatos tecnológicos à serviço do fenômeno turístico não estão isolados de disputas de poder entre os diferentes grupos sociais envolvidos. Uma vez que a neutralidade tecnológica inexiste, pois, segundo Feenberg, (1995, pp. 70-71), a tecnologia em si “(...) não é só o controle racional da natureza: tanto seu desenvolvimento, quanto seu impacto são intrinsecamente sociais".

Ocorre que todas as experiências turísticas, assim como as suas interpretações particulares/coletivas, e o próprio fenômeno turístico em si, podem ser segregárias na medida em que há materializações pautadas em violações da dignidade humana, entrecortadas por marcadores/estereótipos étnicos, raciais, econômicos, políticos, religiosos, de sexo, gênero e classe social. Determina-se, portanto, quem pode ser considerado consumidor turístico e quem não pode.

\footnotetext{
${ }^{1}$ Este entendimento está fundamentado nas considerações sobre cultura de Geertz (2008), ao propor diferentes perspectivas epistemológicas de se pensar culturas para a antropologia e para o exercício da etnografia. Uma vez que para Geertz (2008), tanto os signos, significados, movimentos da cultura e os grupos sociais envolvidos devem ser interpretados em estreita relação com o que acontece. Portanto inexiste um distanciamento do que se quer interpretar com o contexto real da ação, prática e/ou fato, o que para o fenômeno turístico é de suma importância ao se defender movimentos mais democráticos e inclusivos.

${ }^{2}$ Entende-se a intersubjetividade em um movimento dialético/dialógico de reconhecimento de um sujeito. Esta intersubjetividade é prejudicada a partir do momento em que se menosprezam as experiências do outro, negando-lhe consequentemente a sua própria condição como pessoa. Esta ontologia negativa, imposta a determinados grupos sociais/indivíduos, não somente alimentam estigmas, mas servem como elementos fundantes para se cometer atos de violência (cf. construtos/teorizações sobre intersubjetividades, estigmas e sujeitos pensados por Butler, 2015; Goffmann, 1988; Queiroz \& Queluz, 2016).
} 
Sendo assim, estas considerações iniciais servem para problematizar, a nível de Brasil, os estigmas vivenciados/experienciados por pessoas negras que almejam consumir e/ou consomem o turismo, tanto em nível nacional quanto internacional, uma vez que estas pessoas, em conjunto com outras categorias autodeclaradas em censos populacionais brasileiros, totalizam mais de $50 \%$ de uma população de 200 milhões de habitantes ${ }^{3}$, mas que, no entanto, três quartos da população mais pobre do país pertençam a categoria de pessoas autodeclaradas não brancas ${ }^{4}$. Ou quando percebemos que o nível de escolaridade de pessoas não brancas é mais baixo, em comparativo às pessoas autodeclaradas brancas no $\mathrm{Brasil}^{5}$. Ou ainda quando as métricas oficiais evidenciam que a violência no país coloca os homens negros e as mulheres, especialmente as mulheres negras, como grupos sociais mais vulneráveis a atos de violência ${ }^{6}$.

Diante destas considerações iniciais, é apresentada a tese central norteadora deste artigo: de que práticas estruturantes societais de cunho racista, misógino e classista, estão diretamente relacionadas à estigmatizações, preconceitos, violências e discriminações que as pessoas negras brasileiras vivenciam ao consumir o turismo, uma vez que as diferentes formas destas práticas mencionadas são naturalizadas na cotidianidade.

Tem-se então o objetivo central deste texto: tecer uma discussão crítica acerca das vivências/experiências de pessoas negras no turismo, tendo como elementos teóricos balizadores desta tessitura os constructos de tecnologia pensados por Feenberg (1995), bem como, sobre o racismo enquanto uma categoria operada no cotidiano $^{7}$ destes sujeitos estigmatizados.

\footnotetext{
${ }^{3}$ Conforme Instituto Brasileiro de Geografia e Estatística - IBGE (2014).

${ }^{4}$ Conforme IBGE (2014) e Vieira (2016).

${ }^{5}$ De acordo com IBGE (2015) e Instituto de Pesquisa Econômica Aplicada - IPEA (2014), apenas 9,6\% de homens e mulheres autodeclaradas não brancas declararam ter concluído o ensino superior no país. Já pessoas brasileiras autodeclaradas brancas, ainda de acordo com as métricas destes institutos, totalizaram $22,2 \%$ de estudantes concluintes, entre homens e mulheres.

${ }^{6}$ Estudo elaborado por Cerqueira, Lima, Bueno, Valencia, Hanashiro, Machado e Lima (2017) para o Instituto de Pesquisa Econômica Aplicada (IPEA), revelou que negras e negros brasileiros são os grupos sociais mais suscetíveis a sofrerem violências diversas e mortes violentas. No ano de 2015, ainda de acordo com a publicação do IPEA produzida por Cerqueira et al. (2017), revelou que 65,3\% do total de mulheres mortas no Brasil eram negras.

${ }^{7}$ Conforme o conceito de Racismo Cotidiano, elaborado pela antropóloga e cientista social afro holandesa Essed (2010)
} 


\section{O RACISMO NA COTIDIANIDADE, O FENÔMENO TURÍSTICO E A}

\section{TECNOLOGIA COMO SUPORTE DISRUPTIVO}

Ao analisar as tessituras sociais e psicológicas que permeiam as relações afetivas/sexuais entre um homem negro e uma mulher branca, Fanon (2008), a partir de minuciosa interpretação de alguns textos literários de sua época e características psicossociais de suas personagens, apresenta de forma escalar os estágios de um sujeito negro ser reconhecido como branco pela sociedade e sua amada mulher branca, de forma que

Não quero ser reconhecido como negro e sim como branco. (...) amando-me ela me prova que sou digno de um amor branco. Sou amado como um branco. Sou um branco. Seu amor abre-me o ilustre corredor que conduz à plenitude... (Fanon, 2008, p. 69).

Esta escala pensada pelo autor parece ser constituída pelos estágios do desejo de ser reconhecido como (1) sujeito branco, (2) de ser amado como esse sujeito ama seu semelhante branco, (3) de se apropriar da identidade desse sujeito e (4) dessa identidade conduzir a uma plenitude emancipatória, de forma que a plenitude se manifeste. O autor afirma: “(...) é da civilização branca, da dignidade branca que me aproprio" (Fanon, 2008, p. 69).

Apesar do próprio autor alertar, nas primeiras páginas de seu livro, acerca da temporalidade e escopo analítico situado de um escritor antilhano e sua obra, é possível estabelecer conexões entre uma condição ontológica negativa ${ }^{8}$ imputada às pessoas negras a partir da matriz racial/colonial branca/europeia, com os processos operativos do racismo no cotidiano de sujeitos estigmatizados, este pensado no texto de Essed (2010).

Para esta autora, o racismo se trata de um sistema que, enquanto instrumento de poder complexo e operativo em suas práticas, pode ser consciente ou não nas relações sociais cotidianas, retroalimentado em si mesmo.

Por conseguinte, o racismo se define como um conjunto de cognições, ações e procedimentos que contribuem ao desenvolvimento e a perpetuação de um sistema pelo qual os brancos dominam os negros. Observe-se que a dominação racial, como assinalei anteriormente, interatua com as forças dinâmicas da dominação de gênero e

\footnotetext{
${ }^{8}$ É possível entender ontologia, a partir das considerações do filósofo, ativista, músico e professor brasileiro Queiróz (2013), sendo esta o sentido abrangente dos sujeitos e do ser em si, tornando possíveis as suas múltiplas (r) existências, operadas pelos discursos produzidos. Já a ontologia negativa, ainda de acordo com este autor, seria o contraponto do não ser em si, imposto à determinados grupos sociais/indivíduos, também operados por discursos produzidos por grupos dominantes. É importante dizer que este ser em si só é constituído a partir do outro, de acordo com interpretações acerca do sujeito, postas nos textos de Butler (2015), Fanon (2008) e o já citado acima Queiroz (2013). Do mesmo modo, é possível afirmar que esta negação ontológica do ser também é dada pelo outro, o que abre caminhos para justificação de violências diversas (Queiroz, 2013; Butler, 2015; Fanon, 2008).
} 
de classe (Essed, 2010, p. 132) 9 .

Destarte, para Essed (2010) ${ }^{10}$, este sistema epistêmico racista só tem um sentido e uma função social na medida em que as suas manifestações são analisadas dentro de práticas/vivências em sua totalidade. Ou seja: este sistema epistêmico está mais além de uma instituição, de um plano individual/cognitivo, biológico ou mesmo de gênero.

(...) o racismo cotidiano pode ser definido como um processo no qual: a) as noções racistas socializadas se incorporam a significados que voltam as práticas imediatamente definíveis e manejáveis; b) as práticas com implicações racistas se voltam em si mesmas familiares e repetitivas; c) as relações raciais e étnicas subjacentes se materializam e se reforçam através destas práticas rotineiras ou familiares nas situações da vida cotidiana (Essed, 2010, p. 148).

Pensando nestas considerações teóricas e no conceito de racismo cotidiano trazido por Essed (2010), fica um questionamento: em que medida estes elementos se manifestam no fenômeno turístico?

A resposta perpassa, primeiro, por entender o turismo enquanto um conjunto de práticas relacionadas a um tempo, contexto histórico e práticas/interrelações entre o visitante, a infraestrutura turística oferecida, o destino turístico em si e a comunidade. Significa dizer que, mais além de um entender um turismo enquanto uma face econômica, comumente materializada/priorizada por agências de fomento oficiais, estado e mercado, é preciso pensálo enquanto um saber-fazer, uma epistemologia em movimento (Ferreira \& Casagrande, 2018; Moesch, 2002).

Deste modo, pensar o fenômeno turístico requer observar como pensar em intersubjetividades entre visitante e comunidade de forma que estas sejam não-artificiais, não privilegiando somente o fomento e o fluxo/dividendos econômicos conforme bem pontua Krippendorf (2001), em sua análise sociológica do fenômeno turístico. Moesch (2002, p. 41) pode auxiliar também nesta resposta, ao exemplificar em pensar o turismo apenas pela economia e publicidade, em detrimento do elemento humano nas experienciações turísticas

A este sujeito são negados os dois elementos da vida humana: a prosa e a poesia. A poesia é um modo de viver na participação, no amor, no fervor, na comunhão, na

\footnotetext{
9 Texto que originou a tradução: Por consiguiente, el racismo se define como un conjunto de cogniciones, acciones y procedimientos que contribuyen al desarrollo y la perpetuación de un sistema en el cual los blancos dominan a los negros. Obsérvese que la dominación racial, como lo señalé anteriormente, interactúa con las fuerzas dinámicas de la dominación de género y de clase (Essed, 2010, p. 132).

${ }_{10}$ Texto original, onde se respeitaram os grifos da autora: (...) el racismo cotidiano puede definirse como un proceso en el cual: a) las nociones racistas socializadas se incorporan a significados que vuelven las prácticas inmediatamente definibles y manejables; b) las prácticas con implicaciones racistas se vuelven en sí mismas familiares y repetitivas; c) las relaciones raciales y étnicas subyacentes se materializan y se refuerzan a través de estas prácticas rutinarias o familiares en las situaciones de la vida cotidiana (Essed, 2010, p. 148).
} 
exaltação, no rito, na festa, na embriaguez, na dança, no canto que, efetivamente, transfiguram a vida prosaica, feita de tarefas práticas, utilitárias, técnicas.

Neste sentido, é importante o estudo de Edelman e Luca (2014) acerca de como as tecnologias não estão imunes em si mesmas, especificamente ao analisar comportamentos de usuários/as e anfitriões/ãs de hospedagem do aplicativo Airbnb ${ }^{11}$. Os autores evidenciaram em seu estudo que as hospedagens compartilhadas que pertencem a pessoas brancas são, em média, $12 \%$ mais caras do que as oferecidas por pessoas negras. Outro dado evidenciado no estudo de Edelman e Luca (2014) é o que aponta que, embora o aplicativo estadunidense tenha em seus princípios o rechaço a quaisquer formas de discriminações, a Air Bed and Breakfast - Airbnb (2020) pouco faz diante de situações onde hóspedes vivenciaram situações de discriminação étnica, racial e/ou de gênero, uma vez que são os próprios usuários quem alimentam os dados solicitados, sendo a plataforma online apenas uma mediadora.

Um desdobramento deste mesmo estudo, realizado por Edelman, Luca e Svirsky (2017), destacou que pessoas com nomes tipicamente pertencentes à comunidade negra estadunidense têm $16 \%$ menos chances de serem aceitas como hóspedes por anfitriões/ãs que divulgam seus anúncios na Airbnb (2020). Importante ressaltar que, tanto o estudo publicado em 2014 quanto o publicado em 2017, ressaltam que mecanismos do design da Airbnb (2020) podem favorecer situações de discriminações e preconceitos.

Feenberg (1995) é pertinente para estas provocações teóricas acerca da tecnologia como um elemento disruptivo, bem como para corroborar com os argumentos descritos no estudo de Edelman e Luca (2014) e Edelman, Luca e Svirsky (2017). Feenberg (1995) defende a necessidade de uma interpretação da tecnologia como quaisquer outros artefatos culturais produzidos, interpretação esta realizada por cientistas, teóricos/as, governos e demais instituições. Para este autor, a disruptura epistemológica da tecnologia ocorre no momento em que a interpretação é hermenêutica.

\footnotetext{
Nesse caso, a tecnologia não é somente um simples servidor de algum propósito social predefinido; é um ambiente dentro do qual um modo de vida é elaborado. Em suma, as diferenças do modo como os grupos sociais interpretam e usam objetos técnicos não são meramente extrínsecas, mas produzem uma diferença na própria natureza destes objetos (Feenberg, 1995, p. 79).
}

A interpretação hermenêutica da tecnologia, para Feenberg (1995), perpassa em operacionalizá-la democraticamente, de modo que esta operacionalização democrática remete

11 Se trata de um serviço oferecido online às pessoas que buscam hospedagens. Tem como características o espírito comunitário, uma vez que grande parte de suas acomodações são em residências de residentes do destino a ser visitado. Outro diferencial deste serviço reside nos preços praticados em relação às formas de hospedagens mais tradicionais. Surgiu no ano de 2008 na cidade de São Francisco, em território estadunidense. Link para consulta: https://www.airbnb.com (Airbnb, 2020). 
a estender as disciplinaridades postas ao desenvolver conhecimentos, em favor de uma emancipação efetiva dos sujeitos, e não uma emancipação parcial para quem detém os meios de produção tecnológicos.

Portanto urge pensar a tecnologia enquanto um elemento para além das materializações do artefato consumido/produzido pelos sujeitos e instituições às quais pertencem, sendo possível relacioná-la com as ponderações teóricas do conceito de racismo cotidiano, proposto por Essed (2010): urge uma interdependência analítica entre as materializações do artefato, seus processos, técnicas e metodologias empregadas historicamente, e as diferentes disputas de poder que influenciaram seus usos, subjugações e dominações de espaços/sujeitos, travestidos em um discurso de neutralidade, objetividade e racionalidade operado na cotidianidade das relações sociais ${ }^{12}$.

Também é possível verificar as aproximações entre o conceito de racismo cotidiano de Essed (2010), e o modo como se problematiza a tecnologia, proposto por Feenberg (1995), embora partam de matrizes epistemológicas diferentes ${ }^{13}$. É possível dizer, com base na autora afro holandesa e autor estadunidense, que determinados conhecimentos produzidos estão seguramente pautados em modos de subjugação sistemática de determinados grupos sociais, materializados em seu corpo, seus modos de ser e viver e, por fim, de tecnologias pensadas

12 A matéria jornalística online, escrita por Carolina Scorce em 2018, é ilustrativa para entender a discussão proposta neste artigo: que diferentes tecnologias foram empregadas por agentes públicos do tempo do império brasileiro para apagar os espaços utilizados na tortura e assassinato de inúmeros negros e negras, durante o período de escravização oficial brasileira. Para tal, Scorce (2018) entrevista uma pesquisadora do campo da Biblioteconomia, acerca dos apagamentos destes espaços de tortura de pessoas negras no hoje conhecido bairro paulistano da Liberdade, bairro este que celebra as diferentes culturas orientais. Mas que não preservou os espaços destinados à prisão, tortura e morte de escravos nesta região. As outrora edificações e espaços públicos foram ressignificados e/ou destruídos, em uma tentativa de invisibilizar as atrocidades ocorridas, embora estas estivessem vivas na memória de moradoras e moradores antigos/as. Outro exemplo é trazido em matéria de Sergio Matsuura, também de 2018, ao apresentar a polêmica de um móvel criado por um grupo de marceneiros e um designer brasileiros. Este móvel doméstico, com a finalidade para guardar louças, teve inspiração de design no tronco, instrumento utilizado para torturar escravos. Pensar a tecnologia a partir das considerações teóricas de racismo cotidiano propostas por Essed (2010), remete a questionar a neutralidade, racionalidade e intencionalidade dos processos técnicos empregados, do artefato em si, das visões de mundo dos sujeitos, conforme Feenberg (1995) destaca em seus textos ao falar mais diretamente sobre a temática. Cabe destacar que os links das matérias jornalísticas produzidas por Scorce (2018) e Matsuura (2018) se encontram nas referências deste artigo.

13 Enquanto Essed (2010) parte primariamente de constructos da sociologia, de epistemologias feministas do ponto de vista, de fundamentos da análise do discurso e da psicologia, ao tecer seu conceito de racismo cotidiano, evidenciando as diferentes camadas de opressões que pessoas negras sofrem (especialmente as mulheres negras) em suas interações cotidianas, Feenberg (1995) perfaz reflexões da Teoria Crítica. Se trata de um campo do conhecimento, surgido no século XX, que ampliou os construtos marxistas do processo de produção e conformação dos diferentes sujeitos ao sistema capitalista. A perspectiva de Feenberg (1995) pode ser entendida em uma perspectiva analítico/interdisciplinar e defensora de princípios radicais democráticos do conhecimento em todos os escopos societais, não somente a quem detém os meios produtivos. A crítica de Feenberg (1995) é que mesmo as experiências socialistas vivenciadas no século XX não foram capazes de promover esta radicalização da democracia do conhecimento e, por conseguinte, da tecnologia produzida. 
para determinar experiências/vivências diversas. A tecnologia é a sociedade e a sociedade é a tecnologia ${ }^{14}$.

\section{O PERCURSO METODOLÓGICO}

Com relação à natureza metodológica deste artigo: se trata de um estudo interpretativo, situado/localizado e bibliográfico. Portanto esta é uma pesquisa eminentemente qualitativa, uma vez que, a partir de Moreira e Caleffe (2008, p. 73), uma “(...) pesquisa qualitativa explora as características dos indivíduos e cenários que não podem ser facilmente descritos numericamente". Significa dizer que estes tipos de fundamentos metodológicos fornecem alternativas para investigações em ciências humanas, escapando a análises eminentemente positivistas e prioritariamente quantitativas de fenômenos.

Cabe dizer que a tessitura teórica e as problematizações pensadas para este artigo, se basearam em uma leitura primeira de indicadores/métricas de agências de fomento de turismo brasileiras (embora não sejam aqui apresentados) ${ }^{15}$, bem como de três relatos transcritos online, de uma empresa de acomodações de hospedagens brasileira voltada à pessoas negras ${ }^{16}$, sempre buscando um entrelaçamento entre uma tecnologia disruptiva e os mecanismos de operação do racismo cotidiano vivenciados pelas pessoas negras consumidoras/produtoras de turismo.

Neste sentido, o trabalho divide-se, após as considerações introdutórias, balizadores teóricos e esta explicação do caminho metodológico, em dois movimentos reflexivos. O primeiro deles tratou de caracterizar a empresa e sua proposta de experiências/vivências no turismo para pessoas negras. Ao mesmo tempo, este primeiro movimento reflexivo tratou de analisar os excertos públicos, disponíveis online e devidamente transcritos, de relatos de pessoas negras que vivenciaram situações dolorosas de racismo, ao experienciarem o turismo. As transcrições ocorreram entre maio e novembro de 2018. Cabe dizer que as análises das

14 Donna Haraway, de 2009, em seu Manifesto Ciborgue, aborda as aproximações, tensões, silenciamentos e resistências entre o humano e não humano, representado pelos diversos artefatos que materializam o mito do ciborgue pensado pela filósofa estadunidense. Ciborgue este que pode ser disruptivo, quando se pensam em tecnologias voltadas à emancipação integral dos sujeitos, tal como as postulações de Feenberg (1995), ou ciborgue este pensado unicamente para controlar determinados grupos sociais, tal como Haraway (2009) abordou nas diversas estruturas e tecnologias voltadas para manter o patriarcado como primazia analítica, ao tratar das experiências/epistemologias feministas. Embora este texto seja da década de 1980 e não seja elemento teórico analítico utilizado neste artigo, é pertinente pensar que a tecnologia também se materializa a partir dos corpos.

${ }^{15}$ Conforme Associação Brasileira das Operadoras de Turismo (Braztoa), Ministério do Turismo brasileiro, do Instituto de Pesquisas Econômicas e Aplicadas (IPEA), Instituto Brasileiro de Geografia e Estatística (IBGE) e de artigo produzido por Ferreira e Casagrande (2018).

16 Os relatos transcritos, disponíveis online na plataforma Youtube (2019), concernem à empresa de acomodações de viagens chamada Diáspora Black. 
transcrições foram pensadas a partir do conceito de Racismo Cotidiano de Essed (2010) e as contribuições críticas da tecnologia, em si mesma e para si mesma, de Feenberg (1995).

Já o segundo movimento reflexivo, este interdependente do primeiro e à guisa das considerações finais, concerne a pensar em um outro turismo. Turismo este mais democrático, inclusivo, tolerante e que favoreça intersubjetividades, tendo a tecnologia debatida aqui como uma possibilidade disruptiva em si mesma e para si mesma.

\section{CARACTERIZAÇÃO DA ORGANIZAÇÃO ANALISADA E INTERPRETAÇÃO DOS} RESULTADOS

A Diáspora Black (2020) e a proposta de suas tecnologias empregadas podem ser pensadas como um instrumento tecnológico nas concepções de Feenberg (1995). Esta empresa surgiu no ano de 2016, no Brasil, partindo de experiências de racismo vividas pelos seus três fundadores. Neste sentido, a empresa se define como "uma rede de anfitriões e viajantes interessados em vivenciar e valorizar a cultura negra. Para quem quer se conectar com nossa memória, fortalecer nossas identidades e fomentar engajamento" (Diáspora Black, 2020). Em suas políticas de informação definidas, a empresa assegura não tolerar quaisquer tipos de discriminações e preconceitos, tanto das pessoas que utilizam seus serviços como viajantes/hóspedes de acomodações, quanto dos/as anfitriões/ãs que os/as recebem.

A Diáspora Black (2020), de acordo com seus fundadores, busca pensar em trocas de diferentes intersubjetividades que valorizem o outro em sua complexidade, integralidade e solidariedade, de forma que estes elementos também fazem parte do escopo principal da empresa: oferecer acomodações comunitárias aos/às usuários/as. Possui uma abrangência de 145 cidades em 17 diferentes países.

Nas palavras de um dos fundadores

- Bom: a Diáspora ponto Black, ela surge de experiências, né... de vivências... de tentativas de se hospedarem (pessoas negras), né? De receber pessoas, de vivências de rejeição nessas tentativas. Eh... eu vivi em minha própria casa, tentando receber um casal que ao chegar, eles ficaram visivelmente incomodados quando eu abri a porta e quando eu saí pra comprar algumas frutas, eles deixaram um bilhete dizendo que não era bem o que eles esperavam. De fato, eles não esperavam ser recebidos por um anfitrião negro. E essa experiência não é uma experiência do Carlos, é uma experiência vivida pela população negra: foi identificado por uma pesquisa de Harvard (universidade estadunidense) que comprova que negros e negras tem um índice de rejeição maior em plataformas de acomodação compartilhada. E dessa 
experiência (sua) surge o desejo de criação de uma rede que nos contemplasse, que nos permitisse viver a experiência (do turismo, da viagem, de ser anfitrião/ã) antirracista, anti qualquer tipo de preconceito e que nos desse a segurança de acomodações e acolhidas seguras e boas experiências. Assim nasceu a Diáspora Ponto Black. (Silva, 2018, citado por Youtube, 2019).

Silva (2018, citado por Youtube, 2019), ao problematizar a sua experiência como empresário do ramo de hospedagens, destaca que essa surpresa dos hóspedes em reconhece-lo como anfitrião, está fundamentada em estereótipos do ser negro, o que foi o fator determinante para a criação de uma empresa que a todo instante busca romper com preconceitos em suas relações cotidianas (de usuários/as da plataforma, anfitriões e o próprio mercado turístico).

O relato de Silva (2018, citado por Youtube, 2019) corrobora com as considerações de Essed $(2010 \text {, p. 148 })^{17}$, na medida em que as relações intersubjetivas são pautadas a partir de estereótipos constituídos da negritude, materializados na cotidianidade das relações e com a participação das instituições (especialmente na sociedade brasileira), de maneira que

\begin{abstract}
(...) implica que cada pessoa está involucrada de maneira diferente no processo do racismo cotidiano, dependendo de seu gênero, classe e status, assim como de outros fatores que determinam o conteúdo e a estrutura de sua vida cotidiana. Assim mesmo, cabe assinalar que o processo do racismo cotidiano não somente se leva a cabo através da interação direta com os negros, mas também através do contato indireto. Isto se compreende claramente se se considera, por exemplo, o papel dos responsáveis políticos ou de jornalistas no processo do racismo cotidiano. Na prática imediata de suas vidas cotidianas, os responsáveis políticos formulam e aplicam normas e condições que reforçam a injustiça racial existente [...] os artigos racistas que publicam os jornalistas são parte do processo do racismo cotidiano, que se fundamentam ou não em uma interação direta com os negros (Essed, 2010, p. 148).
\end{abstract}

Assim, o exemplo trazido para este artigo do Diáspora Black (2020), é pertinente para esta discussão teórica quando $67 \%$ das pessoas que acessam este aplicativo brasileiro, são compostas por mulheres negras que “(...) não só nos ajudaram a desenvolver o Diáspora, financiando a campanha [de fomento de recursos/parceiras e parceiros para acomodação de espaços], mas que hoje ajudam fazendo parte desta rede" (Silva, 2018, citado por Youtube,

17 Texto originario da tradução: (...) implica que cada persona está involucrada de manera diferente en el proceso del racismo cotidiano, dependiendo de su género, clase y estatus, así como de otros factores que determinan el contenido y la estructura de su vida cotidiana. Asimismo, cabe subrayar que el proceso del racismo cotidiano no sólo se lleva a cabo a través de la interacción directa con los negros, sino también a través del contacto indirecto. Esto se comprende claramente si se considera, por ejemplo, el papel de los responsables políticos o de los periodistas en el proceso del racismo cotidiano. En la práctica inmediata de sus vidas cotidianas, los responsables políticos formulan y aplican normas y condiciones que refuerzan la injusticia racial existente (...) los artículos racistas que publican los periódicos son parte del proceso del racismo cotidiano, que se fundamenten o no en una interacción directa con los negros (Essed, 2010, p. 148). 
2019).

Também é possível estabelecer relações entre o relato de Silva (2018, citado por Youtube, 2019) e as considerações de Feenberg (1995, p. 77), ao criticar a tecnologia enquanto elemento funcionalista. Para este autor, o “(...) papel social de um objeto técnico e os estilos de vida que ele torna possível", só são perceptíveis na medida em que se traz a tecnologia e seus artefatos produzidos/consumidos para um contexto social e para a concretude das necessidades dos sujeitos.

As discriminações sofridas por uma pequena parcela da população negra brasileira, que têm condições econômicas de consumir determinados serviços turísticos, ainda se vê invisibilizadas em razão de estereótipos que reforçam a sua ontologia negativa pessoal/personal e, ao mesmo tempo, enquanto um grupo social, materializando a cotidianidade do racismo. Foram estas vivências que, nas palavras de Silva (2018, citado por Youtube, 2019), motivaram a criação de um serviço virtual de hospedagens que valorizasse a intersubjetividade entre as pessoas negras.

Destarte, o relato de Silva (2018, citado por Youtube, 2019), acerca das limitações de outros ambientes virtuais de hospedagem que corroboraram para estigmatizar pessoas negras como não pertencentes ao universo do ideal do ser turista, também podem ser conectadas com o conceito de racionalização subversiva da tecnologia, proposta por Feenberg (1995, p. 92): remete ao chamamento da “ (...) responsabilidade da ação técnica quanto aos contextos humanos e naturais".

Significa dizer, a partir de Feenberg (1995), que a tecnologia, suas técnicas, processos e artefatos produzidos/consumidos devem ser pensados levando em consideração todos os grupos sociais e espaços de convivência em condições democráticas, interdependentes e de equidade, diferentemente da dicotomia sujeito-natureza proposta pela visão tecnológica tradicional combatida pelo autor. É possível dizer que o Diáspora Black (2020) pode ser considerado um exemplo de ressignificação da função de um ambiente tecnológico, a partir da racionalização subversiva proposta por Feenberg (1995).

Outro depoimento, transcrito para este texto, é de uma usuária negra do referido aplicativo para pessoas negras. Em uma viagem a trabalho realizada para uma cidade do Estado do Rio de Janeiro, a usuária relatou uma experiência negativa vivenciada em um hotel

- Eu fui fazer um especial [reportagem] sobre Angra dos Reis e tinha uma grande rede hoteleira que acabou acolhendo a equipe, né... enfim... eu tinha uma entrevista com o prefeito [de Angra dos Reis] no dia seguinte e tal... e fiquei o dia inteiro trabalhando neste especial de 
Angra dos Reis. Quando cheguei no hotel à noite, eu tava com uma... por acaso a minha produtora também é uma mulher negra. E nos duas estávamos no hotel, chegamos meia noite, pedimos uma sopa e, quando o garçom chegou e que abriu a porta, ele fez a primeira pergunta: 'vocês são babás?' Aí eu disse: 'não, não somos'. Ai ele: 'porque vocês parecem babás. Isso é muito normal aqui. Os hóspedes vão colocar as babás no quarto ao lado' (Barreto, 2016 citado por Youtube, 2019).

Aqui é importante fazer um aparte analítico acerca da maioria das pessoas usuárias do Diáspora Black (2020) serem as mulheres, novamente tomando como referência principal Essed (2010). Para esta autora, é importante entender o racismo enquanto ideologia, estrutura e processo: estes três componentes se entrelaçam em uma tessitura social, determinada hierarquicamente e, a partir de uma norma estabelecida, classifica quem seriam os grupos sociais deterministicamente depreciados em razão de suas características culturais e biológicas.

E, pensando a partir destes elementos trazidos por Essed (2010) acerca do racismo e a ideia de raça, enquanto um sistema atrelado à lógica capitalista/colonial, é possível estabelecer relações com o que a historiadora e filósofa Lélia Gonzáles (1984) debateu em um texto da década de 1980 acerca do racismo e sexismo presentes na cultura brasileira, especialmente às mulheres negras, onde

\begin{abstract}
O fato é que, enquanto mulher negra, sentimos a necessidade de aprofundar nessa reflexão, ao invés de continuarmos na reprodução e repetição dos modelos que nos eram oferecidos pelo esforço de investigação das ciências sociais. Os textos só nos falavam da mulher negra numa perspectiva sócio-econômica que elucidava uma série de problemas propostos pelas relações raciais. Mas ficava (e ficará) sempre um resto que desafiava as explicações. E isso começou a nos incomodar. Exatamente a partir das noções de mulata, doméstica e mãe preta que estavam ali, nos martelando com sua insistência... [...] E o risco que assumimos aqui é o do ato de falar com todas as implicações. Exatamente porque temos sido falados, infantilizados (infans, é aquele que não tem fala própria, é a criança que se fala na terceira pessoa, porque falada pelos adultos), que neste trabalho assumimos nossa própria fala. Ou seja, o lixo vai falar, e numa boa (Gonzáles, 1984, p. 225. Grifos da autora).
\end{abstract}

Embora haja um escopo temporal entre os textos de Essed (2010) e Gonzáles (1984), é interessante perceber como os diálogos convergem: as mulheres e especialmente as mulheres negras, as violências estão materializadas pela dificuldade em percebê-las em outros lugares que não subalternizados dentro de uma tessitura social, onde o fato de ser mulher e ser negra é preponderante para autorização de práticas racistas na cotidianidade das relações. Do mesmo modo, o estudo acerca da pouca atenção dada por órgãos governamentais frente as violências sofridas por viajantes mulheres, de Piscitelli (2017), também podem ser postas neste aparte 
analítico, corroborando com os conceitos centrais trazidos por Essed (2010) e Feenberg (1995): o fato das mulheres serem a maioria de usuários do Diáspora Black (2020), 67\%, pode ser um sinal de que a maior aderência à plataforma de hospedagens está relacionada diretamente a experiências positivas de gênero e raciais vivenciadas, aliadas à segurança de sua integridade física e mental.

Feito este aparte analítico, mas de fundamental importância para a discussão deste artigo, é interessante perceber que, tanto a fala transcrita de Silva (2018, citado por Youtube, 2019) quanto a de Barreto (2016, citado por Youtube, 2019) pode ser corroborada com o conceito de racismo cotidiano de Essed (2010), na medida em que as manifestações de cunho racista, e no caso em específico de Barreto (2016, citado por Youtube, 2019), também misóginas, são retroalimentadas na estrutura sistêmica das relações sociais de acordo com cada especificidade da situação vivenciada, do sujeito e da instituição mediada, o que é diferente de apenas se pensar no racismo apenas no campo individual e/ou institucional.

Significa dizer que estas situações concretas vivenciadas fazem parte de uma tessitura social sistêmica que é reforçada na cotidianidade das relações entre os diferentes sujeitos, de forma que a tecnologia também não está alheia a esta dinâmica, conforme é possível perceber neste outro relato de um viajante negro brasileiro, ao denunciar a dificuldade em conseguir alugar hospedagens para si em plataformas tradicionais e/ou online

- O fluxo de solicitação, de pedido, ele é muito baixo... quando está partindo do meu perfil, da minha foto. E... a partir da imobiliária, né... de uma pessoa jurídica... ou até mesmo a partir de uma pessoa física, de uma amiga que eu confio bastante (e ela é branca), o fluxo é bem maior! (França, 2016, citado por Youtube, 2016).

Percebe-se que os espaços virtuais de partilhas experienciais, trazidos para este artigo, corroboram com as possibilidades disruptivas da tecnologia pensadas por Feenberg (1995), ao passo que as diferenças culturais entre sujeitos e grupos sociais são materializadas através de tecnologias que abrem possibilidades de comunicação não tradicionais, existências e resistências diversas. Muda-se, assim, a tecnologia em si mesma. Mais do que isto: problematizam-se as relações sociais a partir da cotidianidade, evidenciando estruturas racistas, misóginas e classistas, por vezes ocultas nas regras do tecido social vigente e suas instituições diversas, conforme bem argumenta Essed (2010). 


\section{5. É POSSÍVEL UM OUTRO TURISMO?}

Da mesma forma que Krippendorf (2001) sustentou em seu texto que o fenômeno turístico não pode ser pautado apenas pelo viés econômico e pelo fomento de destinos, sob pena de reduzir as experiências do/da viajante, da comunidade e dos próprios espaços a meras representações estatísticas, Moesch (2002) critica fortemente pensar o fenômeno turística enquanto concepções deterministas e fixas, tanto por centros de produção do conhecimento, quanto os próprios órgãos governamentais e não governamentais

O "iluminismo" do campo teórico turístico, emergente na década de 1970 e persistente nas publicações da Organização Mundial do Turismo, por meio de seus anuários estatísticos, no fazer-saber do turismo, solapa a dinâmica complexa da interdisciplinaridade deste fenômeno pós-moderno (Moesch, 2002, p. 133).

Neste contexto e conforme Krippendorf (2001) e Moesch (2002), importa problematizar as campanhas publicitárias veiculadas e as representações dos sujeitos ${ }^{18}$; questionar também porque não se prioriza outras características que não somente o fluxo de visitantes, seus países de origem e/ou regiões brasileiras, tempo médio de permanência no lugar e volume de gastos $^{19}$.

A construção de experiências positivas do fenômeno turístico perpassa não apenas pelo valor simbólico que cada elemento é dado por quem viaja, mas também por ambientes onde as intersubjetividades não são artificiais e/ou segregárias, determinando quem pode ou quem não pode frequentar determinados espaços, corroborando com as problematizações teóricas propostas por Ferreira e Casagrande (2018), ao pensar em turismos democráticos e inclusivos. Estigmatizam-se sujeitos em razão de sua cor de pele, cultura, língua, diversidade étnica, moral, sexual, afetiva, geracional e/ou cognitiva.

Estes elementos estigmatizadores retroalimentam um sistema classista, racista e misógino, conforme bem evidenciou Essed (2010) ao desenvolver seu conceito de racismo operante na cotidianidade e para além do campo individual ou institucional. Uma vez que as

18 O estudo de Hintze e Junior (2012) problematizou peças publicitárias veiculadas em uma importante revista brasileira do setor de viagens/turismo, evidenciando as representações estereotipadas nas propagandas analisadas do que seria um/a viajante ideal para o destino divulgado. As poucas pessoas negras representadas, conforme o estudo dos autores, além de serem padronizadas nas fotografias de acordo a matriz normativa branca (esquema de cores das fotos, vestuário, características físicas, dentre outros fatores), acabavam sendo invisibilizadas perante o próprio fenômeno turístico, projetando aos consumidores da revista uma imagem falseada dos sujeitos. ${ }_{19}$ Conforme resultados de 2018, do Anuário Estatístico de Turismo, vinculado ao Ministério do Turismo do Brasil (Brasil, 2019) e, mais recentemente, do Anuário Braztoa (2019). Nestas publicações, percebeu-se a primazia por questões de fomento/econômicas (que também são importantes, registre-se) e deixou-se de buscar outras características das viagens e experiências intersubjetivas pensando em questões étnicas/raciais, de classe social, de gênero e cultura, tanto de autóctones quanto de visitantes. Vale destacar que para mulheres viajantes e, especialmente mulheres não brancas viajantes, estas questões são ainda mais complexas de serem pensadas, o que certamente merece uma atenção maior do fenômeno turístico. 
normativas das instituições que regem as vidas das pessoas geralmente primam pela defesa da dignidade humana, porém suas práticas e omissões por quem as representa são, no mínimo, contradizentes/contraproducentes.

Os três depoimentos transcritos apresentados neste artigo e a própria concepção da empresa brasileira Diáspora Black (2020) convergem com a visão de tecnologia proposta por Feenberg (1995), ao se pensar em plataformas online democráticas, de resistências e existências positivas às pessoas negras, de fortalecimento de redes econômicas/solidárias, de ressignificar as dores vivenciadas por ser uma pessoa negra em uma sociedade brasileira, especialmente às mulheres negras, maioria de pessoas que utilizam a plataforma.

Do mesmo modo, os excertos apresentados aqui, acerca dos estudos realizados nos Estados Unidos por Edelman e Luca (2014) e por Edelman, Luca e Svirsky (2017), além de evidenciarem a cotidianidade do racismo, desmontam quaisquer visões neutras e objetivas da tecnologia. Reafirma-se novamente: a tecnologia é a sociedade e a sociedade é a tecnologia. Ademais, experiências positivas como a da Diáspora Black (2020), colocam em forte questionamento a dinâmica das relações entre grupos sociais, forçando as sociedades a reverem suas próprias concepções de sujeito, instituições, democracia, tecnologia e cultura.

A pergunta título que norteou a discussão deste artigo não é simples de ser respondida e tampouco se responde simplesmente de modo dicotômico, uma vez que pensar em outras formas de turismo requer questionar, por exemplo, os currículos de turismo postos nas universidades, interseccionando esses com questões de classe, gênero, etnia e raça, na análise do fenômeno turístico e de suas bases epistemológicas centrais. Também requer mudanças nas sociedades que problematizem questões como acúmulo de riquezas, desigualdades sociais, combinadas à exploração dos destinos turísticos e fluxos migratórios e/ou de viajantes, deixando de reproduzir ou até mesmo criar estereótipos de quem pode ou não viajar.

Portanto, só é possível pensar em um outro turismo quando, de forma não maniqueísta, questionar como é que se dão os diálogos intersubjetivos, indagar por quais motivos naturalizamos comportamentos que violentam o outro e, essencialmente, ter a coragem de compreender a quais custos somos formados enquanto indivíduos e sociedade. 


\section{REFERÊNCIAS}

Air Bed and Breakfast. (2020). Página inicial. Recuperado em 08, abril, 2020, de https://www.airbnb.com.br/

Associação Brasileira das Operadoras de Turismo - Braztoa. (2019). Anuário Braztoa 2019. São Paulo: Braztoa. Recuperado em 19, dezembro, 2019, de http://braztoa.com.br/braztoa/Braztoa_anuario_2019.pdf

Brasil. Ministério do Turismo. (2019). Anuário estatístico de turismo 2019: volume 46 ano base 2018. Recuperado em 19, dezembro, 2019, de http://dadosefatos.turismo.gov.br/201602-04-11-53-05.html

Butler, J. (2015). Relatar a si mesmo: crítica da violência ética. Belo Horizonte: Autêntica.

Cerqueira, D., Lima, R. S., Bueno, S., Valencia, L. I., Hanashiro, O., Machado, P. H. G., Lima, A. S. (2017). Atlas da violência 2017 IPEA e FBSP. Rio de Janeiro: IPEA. Recuperado em 04, outubro, 2019, de http://www.ipea.gov.br/portal/images/170609_atlas_da_violencia_2017.pdf

Diáspora Black. (2020). Sobre. Recuperado em 08, abril, 2020, de https://diaspora.black/manifesto/

Edelman, B. \& Luca, M. (2014). Digital discrimination: the case of Airbnb.com. Harward Business School. Working paper. Retrieved octuber, 01, 2019, from https://www.hbs.edu/faculty/Publication\%20Files/Airbnb_92dd6086-6e46-4eaf-9cea60fe5ba3c596.pdf

Edelman, B., Luca, M., \& Svirsky, D. (2017). Racial Discrimination in the Sharing Economy: evidence from a field experiment. American Economic Journal: Applied Economics, 9(2), 1-22.

Essed, P. (2010). Hacia una conceptualización del racismo como proceso. In: Hoffmann, O., $\&$ Quintero, O. (Orgs.). Estudiar el racismo: textos y herramientas. Cuaderno de trabajo AFRODESC/EURESCL, (8).

Fanon, F. (2008). Pele negra, máscaras brancas. Salvador: EDUFBA.

Feenberg, A. (1995). Do essencialismo ao construtivismo: a filosofia da tecnologia em uma encruzilhada. In: Neder, R. T. (Org.). A teoria crítica de Andrew Feenberg: racionalização democrática, poder e tecnologia. (2010). Brasília: Observatório do Movimento pela Tecnologia Social na América Latina.

Feenberg, A. (1995). Racionalização Subversiva: Tecnologia, Poder e Democracia. In: Neder, R. T. (Org.). A teoria crítica de Andrew Feenberg: racionalização democrática, poder e tecnologia. (2010). Brasília: Observatório do Movimento pela Tecnologia Social na América Latina.

Ferreira, M. A., \& Casagrande, L. S. (2018). E quem disse que não é seu lugar? Por um turismo democrático e inclusivo para negros e negras. Revista Mundi Sociais e Humanidades, $3(2), 1-21$.

Geertz, C. (2008). A interpretação das culturas. Rio de Janeiro: LTC. 
Goffman, E. (1988). Estigma: notas sobre a manipulação da identidade deteriorada. Rio de Janeiro: LTC.

Gonzáles, L. (1984). Racismo e sexismo na cultura brasileira. Revista Estudos Sociais Hoje, 223-244.

Haraway, D. J. (2009). Manifesto ciborgue. Ciência, tecnologia e feminismo-socialista no final do século XX. In: Tadeu, T. (Ed. e Trad.). Antropologia do ciborgue - As vertigens do pós-humano. Belo Horizonte: Autêntica Editora.).

Hintze, H., \& Júnior, A. (2012). Estudos críticos em turismo: A comunicação turística e o mito da democracia racial no Brasil. Revista turismo e desenvolvimento, (7/18), 57-72.

Instituto Brasileiro de Geografia e Estatística. (2014). Estatísticas de gênero: uma análise dos resultados demográficos do censo 2010. Rio de Janeiro: IBGE. Recuperado em 03, outubro, 2019, de https://biblioteca.ibge.gov.br/index.php/bibliotecacatalogo?view=detalhes\&id=288941>.

Instituto Brasileiro de Geografia e Estatística. (2015). Pesquisa nacional por amostra de domicílios: síntese de indicadores 2014/IBGE. Rio de Janeiro: IBGE. Recuperado em 03, outubro, 2019, de https://biblioteca.ibge.gov.br/visualizacao/livros/liv94935.pdf

Instituto de Pesquisa Econômica e Aplicada. (2014). Situação social da população negra por estado. Brasília: IPEA. Recuperado em 03, dezembro, 2019, de https://www.mdh.gov.br/biblioteca/igualdade-racial/situacao-social-da-populacao-negra-porestado-seppir-e-ipea/view

Krippendorf, J. (2001). Sociologia do turismo: para uma nova compreensão do lazer e das viagens. São Paulo: Aleph.

Matsuura, S. (2018). Móvel com referência a instrumento de tortura contra escravos causa revolta nas redes - 'Bufê tronco dos escravos' faz parte de coleção 'Quilombo dos Palmares'. $O$ Globo. Recuperado em 11, setembro, 2019, de https://oglobo.globo.com/sociedade/movelcom-referencia-instrumento-de-tortura-contra-escravos-causa-revolta-nas-redes-22875873

Moesch, M. (2002). A produção do saber turístico. (2a. Ed.). São Paulo: Contexto.

Moreira, H., \& Caleffe, L. G. (2008). Metodologia da pesquisa para o professor pesquisador. Rio de Janeiro: Lamparina.

Piscitelli, A. (2017). "\#queroviajarsozinhasemmedo": novos registros das articulações entre gênero, sexualidade e violência no Brasil. Cadernos Pagu, Campinas, (50).

Queiroz, I. P., \& Queluz, G.L. (2016). Raça, racismo e etnicidade: o legado colonial e seu enfrentamento. In: Luz, N. S., \& Casagrande, L. S. (Orgs.). Entrelaçando gênero e diversidade: múltiplos olhares. Curitiba: UTFPR Editora.

Queiroz, I. P. (2013). Fanon, o reconhecimento do negro e o novo humanismo: horizontes descoloniais da tecnologia. 221f. Tese de Doutorado em Tecnologia, Programa de PósGraduação em Tecnologia, Universidade Tecnológica Federal do Paraná, Curitiba, PR, Brasil.

Scorce, C. (2018). Bairro da Liberdade concentrava espaços de tortura e morte contra os negros na escravidão - pesquisadora explica o que são e onde estão os espaços físicos da memória escravocrata na capital paulista. Carta Capital. Recuperado em 12, outubro, 2019, 
de http://www.cartaeducacao.com.br/entrevistas/liberdade-concentrava-forca-o-pelourinhocadeia-e-o-cemiterio-dos-negros-na-escravidao/

Vieira, I. (2016). IBGE: negros são 17\% dos mais ricos e três quartos da população mais pobre. Rio de Janeiro. EBC Agência Brasil. Recuperado em 12, outubro, 2019, de http://agenciabrasil.ebc.com.br/geral/noticia/2016-12/ibge-negros-sao-17-dos-mais-ricos-etres-quartos-da-populacao-mais-pobre

Youtube. (2016). Por que precisamos do Diáspora Black? Recuperado em 02, outubro, 2019, de https://www.youtube.com/watch?v=ET_mN22Dmvc

Youtube. (2018). Como surgiu a Diáspora Black. Recuperado em 04, outubro, 2019, de https://www.youtube.com/watch?v=iO0v0tSsNRA

Youtube (2019). Porque precisamos do Diáspora Black? Recuperado em 02, outubro, 2019, de https://www.youtube.com/watch?v=ET_mN22Dmvc

FERREIRA, M. A. \& CASAGRANDE, L. S. (2020). Movimentos, tecnologia e pessoas negras: é possível um outro turismo? Revista de Turismo Contemporâneo, 8(1), 149-167. https://doi.org/10.21680/2357-8211.2020v8n1ID19551 